\title{
Enhancement the Adhesion between Epoxy Coating and Rusted Structural Steel by Tannic Acid Treatment
}

\author{
Yang Li $\cdot$ Yuantai Ma $\cdot$ Bin Zhang $\cdot$ Bing Lei $\cdot$ Ying Li
}

Received: 17 February 2014/Revised: 3 April 2014/Published online: 11 September 2014

(C) The Chinese Society for Metals and Springer-Verlag Berlin Heidelberg 2014

\begin{abstract}
An eco-friendly rust converter treatment based on tannic acid was optimized by orthogonal experiment, and the adhesion of the epoxy top-coating system was evaluated. The results showed that the adhesion between the epoxy coating and the rusted steel after treatment was enhanced from 1.93 to $5.97 \mathrm{MPa}$. This adhesion improvement was attributed to the formation of the micro-cracked tannic conversion layer and the increase of the compactness of the rust layer. The failure analysis suggested that the remainder rust was still the key issue for the further adhesion improvement of the coating system.
\end{abstract}

KEY WORDS: Tannic acid; Rust; Adhesion; Orthogonal experiment; SEM; FTIR

\section{Introduction}

A low-cost and efficient method for the protection of steel is the application of a corrosion resistant coating. Among anti-corrosion coatings, the epoxy coating has been widely used due to its superior strength, outstanding bonding with different substrates, good dimensional stability, and longterm corrosion and chemical resistance [1]. Therefore, proper surface preparation plays a vital role in obtaining the perfect surface state. Among the various surface cleaning techniques, sandblasting offers the best level of oxide removal and can provide suitable surface roughness for subsequent anticorrosive painting. However, this technique is expensive and has raised serious health concern for workers. Moreover, because of practical conditions, such as equipment location and geometry, sometimes such

Available online at http://link.springer.com/journal/40195

Y. Li · Y. Ma · B. Zhang · B. Lei · Y. Li ( $₫)$

State Key Laboratory for Corrosion and Protection, Institute of

Metal Research, Chinese Academy of Sciences,

Shenyang 110016, China

e-mail: liying@imr.ac.cn sandblasting method cannot be applied under many circumstances [2,3].

As an attractive alternative to sandblasting, the "rust converter" approach presents advanced ability to clean surface [4]. The "rust converter" can react with iron oxides constructing the proper surface for painting systems [2]. Therefore, such method has become a worldwide trend in anticorrosive technology [5]. Among various rust converters, the tannin has been proposed to the protection of rusted steel due to its eco-friendly performance [6]. Tannin is a polyhydroxy of vegetal origin, and the proximity of hydroxyl groups on the aromatic rings makes it easy to chelate with iron ions [7]. It has been reported that the tannin can transform the rust components such as lepidocrocite, magnetite, and goethite into the adherent products [8-10]. Rahim et al. [8] concluded that the adherent product on the surface was an amorphous ferric tannate with small cracks. The coating apparently penetrated into the rust through the cracks. Consequently, the adhesion of the coating system was improved. Besides, Collazo et al. [9] pointed out that this transformation was accompanied with increasing compactness of the rust layer, which could enhance the cohesion of the rust layer. Therefore cohesion improvement was benefit for increasing the adhesion strength of the coating system. 
Recent studies showed that the tannic acid treatment efficiently enhanced the adhesion between the coating and the substrate through the formation of dense and microcracked tannic conversion layer. Some researchers also tried to add different assistant agents to form the conversion layer. Barrero et al. [11] studied the effect of small molecular alcohol on the transformation process and claimed that the mixture of the alcohol could facilitate deeper penetration of the converter (mainly the tannic acid) into the rust layer, thus the reaction with the inner rust could increase compactness of the rust layer and improve the degree of conversion of the rust, resulting in better adherence.

However, few quantitative and comprehensive reports on the tannic conversion approach are available, especially that the lack of quantitative data and sophisticated formulation provides little guidance on the practical application. Therefore, in this work, a formulation based on tannic acid was optimized by the quantitative analysis of tannic conversion layer for enhancing the adhesion of the coating. The adhesion enhancement mechanism was investigated in order to have an insight into the formulation.

\section{Experimental}

\subsection{Materials}

The structural steel (Q235) was selected in the present investigation, and its composition was listed in Table 1. The steel was cut into the specimens with dimension of $25 \mathrm{~mm} \times 25 \mathrm{~mm} \times 3 \mathrm{~mm}$.

According to the actual construction process of the organic coating treatment for the metal substrate, the samples were sandblasted to white metal (A Sa2.5) following ISO 8501-1: 2007 [12].

The salt spray test was used to obtain quick access to the rust layer on the sample surface in the laboratory. After several experiments, it was found that the composition and structure of the rust layer formed after $72 \mathrm{~h}$ salt spray following the ASTM B117 [13] were similar to the rust layer after 36 months outdoor exposure in the city of Shenyang [14]. Therefore, in our study, before the tannic acid treatment, the samples were exposed for $72 \mathrm{~h}$ in the salt spray chamber. Then the rusted samples were dried in air for $24 \mathrm{~h}$.

The tannic converter solution was brushed on the rusted samples in one layer after removing the loose rust with soft

Table 1 Chemical composition of the structural steel Q235 (in wt\%)

\begin{tabular}{lllllll}
\hline $\mathrm{C}$ & $\mathrm{S}$ & $\mathrm{P}$ & $\mathrm{Mn}$ & $\mathrm{Si}$ & $\mathrm{Cu}$ & $\mathrm{Fe}$ \\
\hline 0.176 & 0.023 & 0.019 & 0.570 & 0.233 & 0.033 & Bal. \\
\hline
\end{tabular}

brush. The samples were dried in air for $12 \mathrm{~h}$ considering two aspects: (1) sufficient time for the reaction between the tannic converter and the rust; (2) fully dry time for the tannic conversion layer.

The epoxy coating was selected as the top coating consisting of E-44 resin as binder, amine as hardening agent, and dimethylbenzene as solvent, which were mixed in the stoichiometric proportions of 1:0.8:0.32 and then stirred by a magnetic stirrer machine and kept idle for $1.5 \mathrm{~h}$ to aging. One layer of the prepared epoxy was brushed on the substrate and cured in an oven for $24 \mathrm{~h}$ at $60{ }^{\circ} \mathrm{C}$. And the average coating thickness was measured by a hand-held electronic gage (PosiTector 6000 of Defelsko) according to ISO 2808 to be $(150 \pm 10) \mu \mathrm{m}[15]$.

\subsection{Design of Orthogonal Experiment}

It is well known that the orthogonally designed experiment is a convenient method to investigate the influences of the multiple factors and optimize parameters on the property $[16,17]$. And the protective performance of the coating depends mainly on the adhesion strength between the coating and the substrate [18, 19].

According to Qian et al. [20] and Wei et al. [21], the sodium molybdate and the citric acid were benefit for improving the rust conversion capability of the tannic acid. Meanwhile, some researchers investigated the influences of different types of alcohol on the adhesion and found that the 50-50 wt\% mixture of isopropyl and tertbutyl alcohol could facilitate deeper penetration of the tannic acid into the rust layer. In this way, the tannic acid would react with the inner rust, not only increase the compactness of the rust layer, but also improve the degree of conversion of the rust, leading to better adherence [11]. In addition, the treating temperature was an important factor influencing the reaction of the tannic acid with the rust. Therefore, the tannic acid, the sodium molybdate, the citric acid, the 50-50 wt $\%$ mixture of isopropyl and tertbutyl alcohol, and the treating temperature were selected as the five marked factors with four levels in the orthogonal-designed experiment, as

Table 2 Levels of the factors used in the experiments

\begin{tabular}{lcccc}
\hline Factor & $\begin{array}{l}\text { Level } \\
1\end{array}$ & $\begin{array}{l}\text { Level } \\
2\end{array}$ & $\begin{array}{l}\text { Level } \\
3\end{array}$ & $\begin{array}{l}\text { Level } \\
4\end{array}$ \\
\hline Tannic acid concentration $(\mathrm{g} / \mathrm{L})$ & 5 & 10 & 15 & 20 \\
$\begin{array}{l}\text { Sodium molybdate concentration } \\
\quad \mathrm{g} / \mathrm{L})\end{array}$ & 1 & 2 & 3 & 4 \\
Citric acid concentration $(\mathrm{g} / \mathrm{L})$ & 1 & 2 & 3 & 4 \\
$\begin{array}{l}\text { Mixture of alcohol concentration } \\
\quad \mathrm{g} / \mathrm{L})\end{array}$ & 5 & 10 & 15 & 20 \\
Temperature $\left({ }^{\circ} \mathrm{C}\right)$ & 20 & 25 & 30 & 35 \\
\hline
\end{tabular}


Table 3 Adhesion strength results of the orthogonal tests

\begin{tabular}{|c|c|c|c|c|c|c|}
\hline $\begin{array}{l}\text { Experiment } \\
\text { nos. }\end{array}$ & $\begin{array}{l}\text { Tannic acid } \\
\text { concentration }(\mathrm{g} / \mathrm{L})\end{array}$ & $\begin{array}{l}\text { Sodium molybdate } \\
\text { concentration }(\mathrm{g} / \mathrm{L})\end{array}$ & $\begin{array}{l}\text { Citric acid } \\
\text { concentration }(\mathrm{g} / \mathrm{L})\end{array}$ & $\begin{array}{l}\text { Mixture of alcohol } \\
\text { concentration }(\mathrm{g} / \mathrm{L})\end{array}$ & $\begin{array}{l}\text { Temperature } \\
\left({ }^{\circ} \mathrm{C}\right)\end{array}$ & $\begin{array}{l}\text { Adhesion } \\
\text { (MPa) }\end{array}$ \\
\hline 1 & 5 & 1 & 1 & 5 & 20 & $2.36 \pm 0.22$ \\
\hline 2 & 5 & 2 & 2 & 10 & 25 & $2.89 \pm 0.49$ \\
\hline 3 & 5 & 3 & 3 & 15 & 30 & $1.83 \pm 0.65$ \\
\hline 4 & 5 & 4 & 4 & 20 & 35 & $4.22 \pm 0.22$ \\
\hline 5 & 10 & 1 & 2 & 15 & 35 & $1.94 \pm 0.48$ \\
\hline 6 & 10 & 2 & 1 & 20 & 30 & $2.70 \pm 0.47$ \\
\hline 7 & 10 & 3 & 4 & 5 & 25 & $2.80 \pm 0.51$ \\
\hline 8 & 10 & 4 & 3 & 10 & 20 & $2.11 \pm 0.20$ \\
\hline 9 & 15 & 1 & 3 & 20 & 25 & $3.27 \pm 0.64$ \\
\hline 10 & 15 & 2 & 4 & 15 & 20 & $2.76 \pm 0.34$ \\
\hline 11 & 15 & 3 & 1 & 10 & 35 & $3.70 \pm 0.70$ \\
\hline 12 & 15 & 4 & 2 & 5 & 30 & $1.95 \pm 0.50$ \\
\hline 13 & 20 & 1 & 4 & 10 & 30 & $2.36 \pm 0.21$ \\
\hline 14 & 20 & 2 & 3 & 5 & 35 & $2.39 \pm 0.56$ \\
\hline 15 & 20 & 3 & 2 & 20 & 20 & $2.22 \pm 0.33$ \\
\hline 16 & 20 & 4 & 1 & 15 & 25 & $3.42 \pm 0.44$ \\
\hline
\end{tabular}

shown in Table 2. Note that all chemicals and reagents used were of analytical grade.

\subsection{Adhesion Test}

A portable pull-off test (Positest AT-A of Defelsko) was used to measure the adhesion of the coating system according to ISO 4624-2002 [22]. The size of the test dolly was $\Phi 20 \mathrm{~mm}$ with a test area of $3.14 \mathrm{~cm}^{2}$. Two-component glue was applied to fix the test dolly to the epoxy coating. To achieve better adhesion between the surfaces of the test dolly and the epoxy coating, the contact surfaces of the dolly and the epoxy coating were polished with 400\# SiC paper before the adhesion test. After cleaning the surfaces with ethanol, the glue was applied and then dried for $24 \mathrm{~h}$ at room temperature. To avoid the adhesion of the epoxy coating on the outside of the test range, the epoxy coating was scoured through to the substrate around the test dolly with a circular hole cutter before running the test [23]. Additionally, six parallel samples were tested, and the final result was the average of the six data, and the standard deviation of each result was analyzed by statistical method.

\subsection{Characterization of the Rust and Tannic Conversion Layer}

A Magna-IR 560 infrared spectrophotometer was used to measure the IR spectra in the range between $500 \mathrm{~cm}^{-1}$ and $1,500 \mathrm{~cm}^{-1}$ with an accuracy of $4 \mathrm{~cm}^{-1}$, and each spectrum was accumulated for 35 times. For IR analysis, the rust layer and tannic conversion layer were scraped off by a blade, and the scraped samples and pure anhydrous $\mathrm{KBr}$ were mixed in a mass proportion of 3:100 and ground to a fine powder in a mortar with a pestle. The mixture was then pressed in a simple die to form a circular disk of about $1 \mathrm{~mm}$ thickness.

The X-ray Photoelectron Spectroscopy (XPS) was used to analyze the compositions of the tannic conversion layer. The XPS spectra were recorded with an ESCALAB250 (Thermo VG) using $\mathrm{Al} K \alpha(1,486.6 \mathrm{eV})$ radiation. Samples were analyzed immediately to keep the surface contamination to the minimum.

The cross-sectional and surface morphologies of the rust and tannic conversion layer were observed by an INSPECT F Scanning electron microscopy (SEM). The cross-sectional specimen was prepared by encapsulating into the PVC pipe filled with epoxy resin. After curing of the epoxy resin, the sample was polished down to 2000\# grade emery paper and polished with terylene.

\section{Results}

\subsection{Orthogonal Experiment}

In the present study, all selected factors were examined using the orthogonal L16 $\left(4^{5}\right)$ design. For each adhesion strength result of the 16 experiments, six parallel samples were tested and the final result was the average value of these six samples, and the standard deviation of each value was analyzed by statistical method shown in Table 3. 
Table 4 Average adhesion strength according to each level of each factor (in MPa)

\begin{tabular}{llllll}
\hline Factor level & $\begin{array}{l}\text { Tannic acid } \\
\text { concentration }\end{array}$ & $\begin{array}{l}\text { Sodium molybdate } \\
\text { concentration }\end{array}$ & $\begin{array}{l}\text { Citric acid } \\
\text { concentration }\end{array}$ & $\begin{array}{l}\text { Mixture of alcohol } \\
\text { concentration }\end{array}$ \\
\hline Level 1 & 2.825 & 2.482 & 3.045 & 2.375 & 2.362 \\
Level 2 & 2.388 & 2.685 & 2.250 & 2.765 & 3.095 \\
Level 3 & 2.920 & 2.638 & 2.400 & 2.487 & 2.210 \\
Level 4 & 2.598 & 2.925 & 3.035 & 3.103 & 3.063 \\
Maximum deviation & 0.532 & 0.443 & 0.795 & 0.728 & 0.885 \\
\hline
\end{tabular}

According to Zhang et al. [24], if the experimental values at the same level in the orthogonal experiments for each experimental factor were added together and then were divided by four (the number of the levels), the average value at the same level for each experimental factor was attained.

The effect of each control factor on the adhesion strength at different levels was separated by means of the orthogonal characteristic of the designed experiments. The mean of the adhesion strength for each level of the control factor was calculated, as shown in Table 4. Figure 1 shows the effect plot of the adhesion strength for each level of the control factor. The optimal combination of control factor levels can be determined by selecting the highest level for each control factor. As shown in the Fig. 1, the best adhesion strength performance was obtained by selecting the combination of control factors when the tannic acid is $15 \mathrm{~g} / \mathrm{L}$, sodium molybdate is $4 \mathrm{~g} / \mathrm{L}$, citric acid is $1 \mathrm{~g} / \mathrm{L}$, mixture of alcohol is $20 \mathrm{~g} / \mathrm{L}$, and treating temperature is $25^{\circ} \mathrm{C}$. However, when the concentrations of the citric acid are 1 and $4 \mathrm{~g} / \mathrm{L}$, it presents the similar adhesion strength (Fig. 1). Considering that the cost in industrial application, $1 \mathrm{~g} / \mathrm{L}$ is adequate. And the actual application temperature, $25^{\circ} \mathrm{C}$, is more favorable than $35^{\circ} \mathrm{C}$ though it presents the similar adhesion strength at both temperatures (Fig. 1). Therefore, the optimum condition selected is adequate for the actual application.

The maximum adhesion strength of the coating system under optimum condition can reach $5.97 \mathrm{MPa}$, which is much higher than that without tannic converter treatment $(1.93 \mathrm{MPa})$.

\subsection{Fourier Transform Infrared Spectroscopy (FTIR)}

Figure 2 shows the FTIR spectrum of the samples for the rust layer. Raman et al. [25] suggested that the bands at $1,150,1,020$, and $750 \mathrm{~cm}^{-1}$ were attributed to absorption of lepidocrocite. Among these bands, $1,020 \mathrm{~cm}^{-1}$ is the strongest and could be considered as the characteristic absorption of lepidocrocite. The FTIR spectra in Fig. 2 suggest that the main component of the rust layer is lepidocrocite.

Figure 3 shows the FTIR spectra of the samples after the tannic converter treatment. Some researchers [26] pointed out that the absorption of the ferric tannate located at $1,429,1,340,1,207$, and $1,086 \mathrm{~cm}^{-1}$. Therefore, after the tannic converter treatment, the main components are lepidocrocite and ferric tannate.

\subsection{X-ray Photoelectron Spectroscopy (XPS)}

Figure 4 shows the XPS core level C1s spectrum of the tannic conversion layer. The $\mathrm{C} 1 \mathrm{~s}$ core level exhibits two peaks with the binding energies at $284.59 \mathrm{eV}$ and $288.14 \mathrm{eV}$, respectively. The peak at $284.59 \mathrm{eV}$ is caused by the pollution during the XPS measurement. The peak at $288.14 \mathrm{eV}$ is attributed to $\mathrm{O}-\mathrm{C}=\mathrm{O}$ in the organic polymer

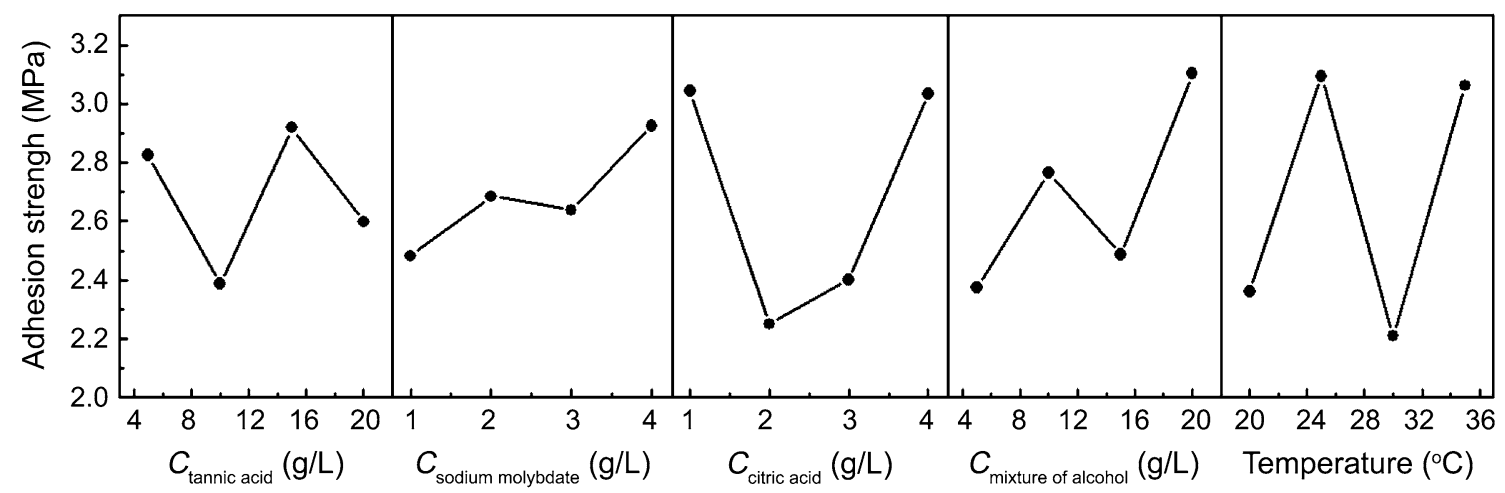

Fig. 1 Effect plots of the adhesion strength for each level of the control factor 


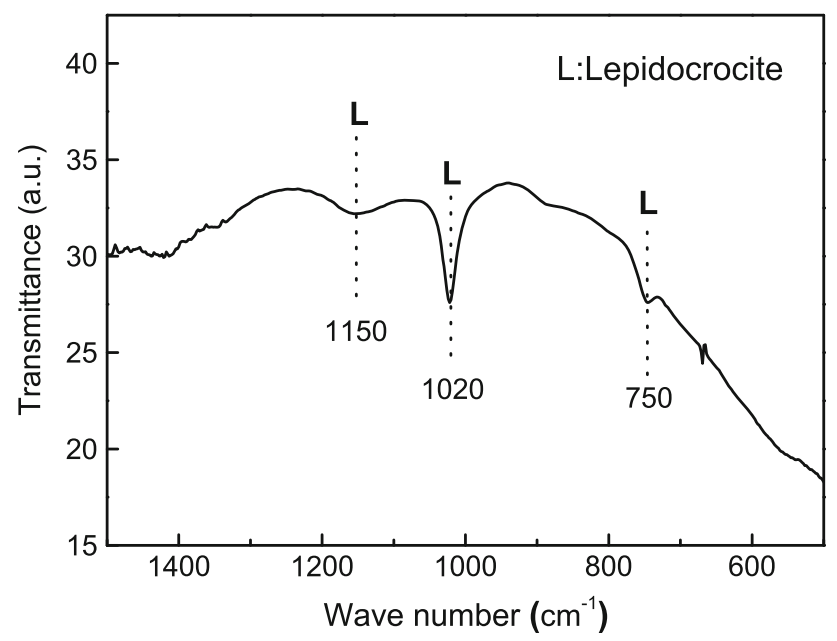

Fig. 2 FTIR spectrum of the rust layer

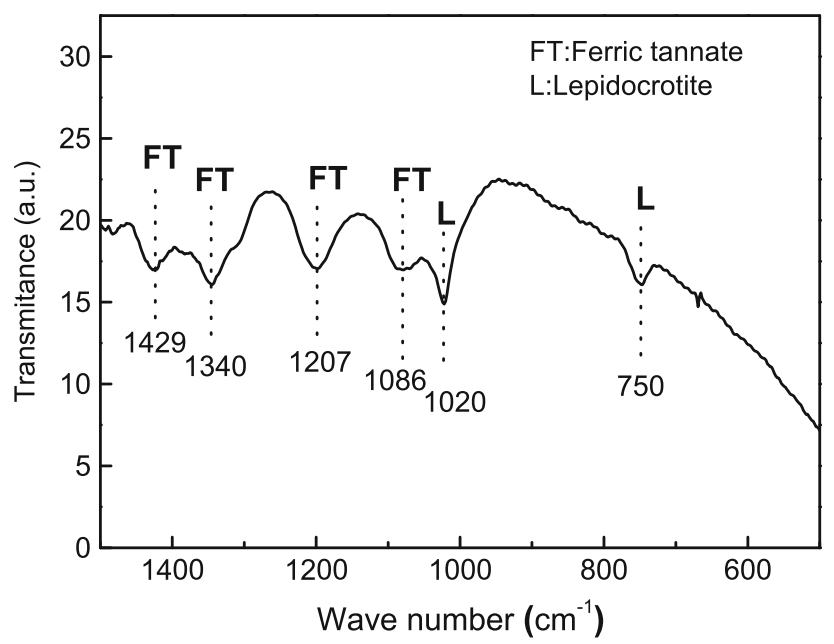

Fig. 3 FTIR spectrum of the sample after tannic converter treatment

[27], which should be the reaction product of the tannic acid.

The detail of Mo3d core level of the tannic conversion layer is shown in Fig. 5, which shows a double-peak feature with the binding energies at 232.14 and $235.38 \mathrm{eV}$, respectively. The two peaks refer to Mo $3 \mathrm{~d}_{5 / 2}$ and $3 \mathrm{~d}_{3 / 2}$ of $\mathrm{MoO}_{x}(2.5<x<3)[28]$.

\subsection{SEM Observation}

Figure 6 presents the representative SEM images of the surface and cross-section morphologies of the rust layer. It can be seen that the rust presents lamellar structure (Fig. 6a) with pores inside the rust (Fig. 6b). According to Smith et al. [29], the lamellar and the porous corrosion product could be lepidocrocite, which is in agreement with the IR result.

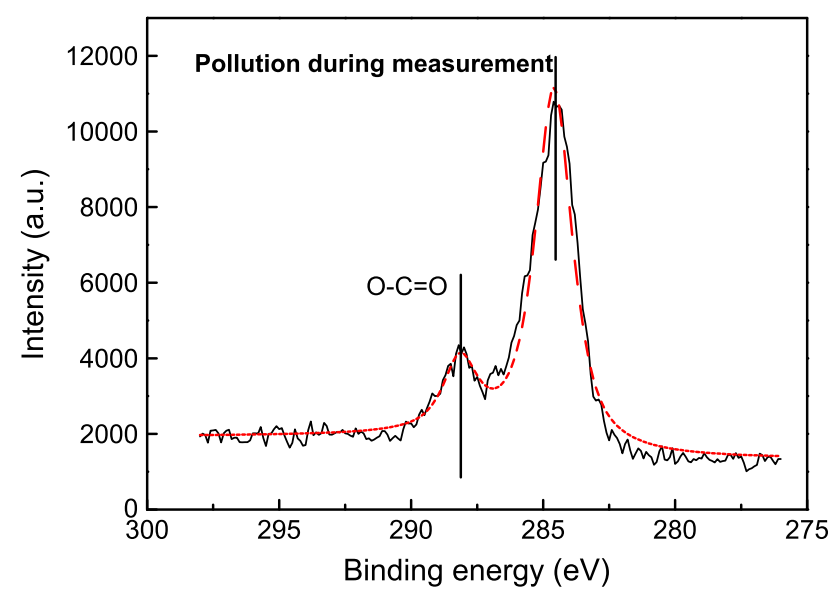

Fig. 4 XPS core level C1s spectrum of the tannic conversion layer

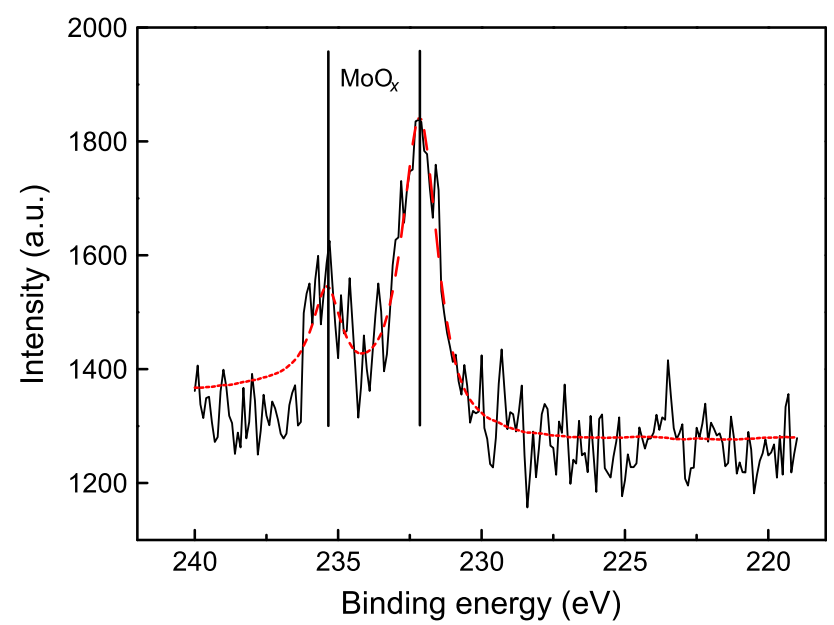

Fig. 5 XPS core level Mo3d spectrum of the tannic conversion layer

After the tannic converter treatment, great changes of the surface and cross-section morphologies were observed. The surface morphology shows the micro-cracks structure (Fig. 7a), which is typical tannic conversion layer [11]. Moreover, the Mo element was detected by EDX measurement (Fig. 7b), indicating that the Mo element was involved in the formation of the conversion layer, which is in agreement with the XPS result. Another important change is that most of the pores inside the rust disappear, leading to the increase in the compactness of the rust layer (Fig. 8). However, a number of the pores could still be seen at the bottom of the rust layer.

\subsection{Failure Analysis}

The failure modes were investigated as they correlated with the adhesion mechanism [30]. There are three kinds of failure modes: (1) interfacial fracture; (2) cohesive 

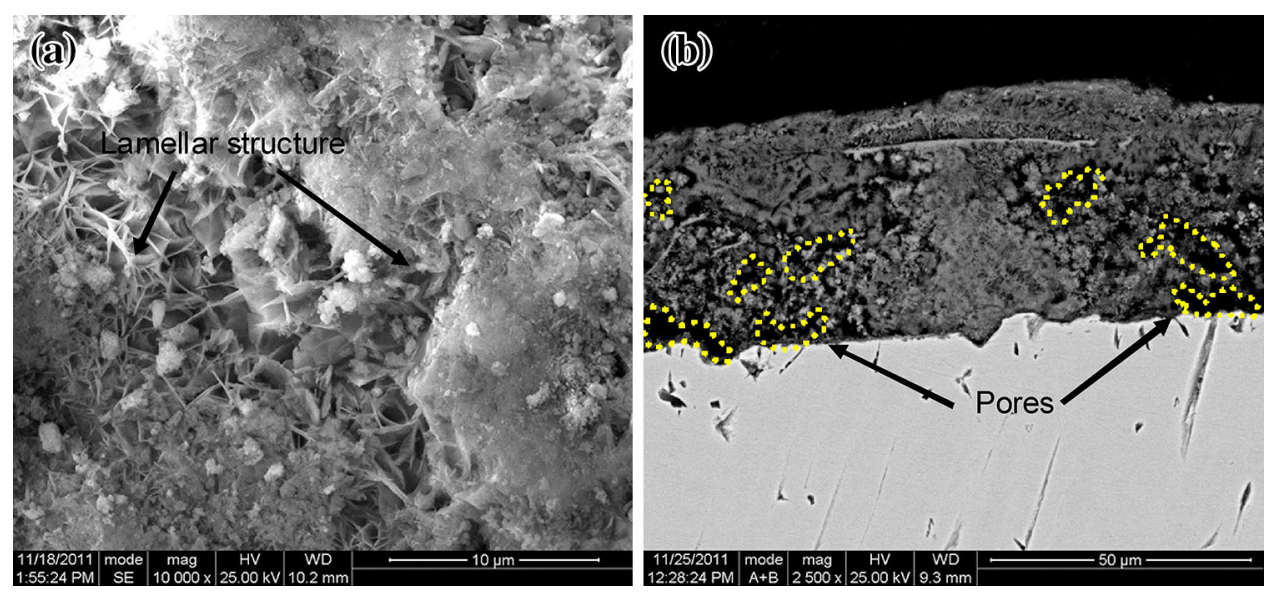

Fig. 6 Surface a; cross-section $\mathbf{b}$ morphologies of the rust layer
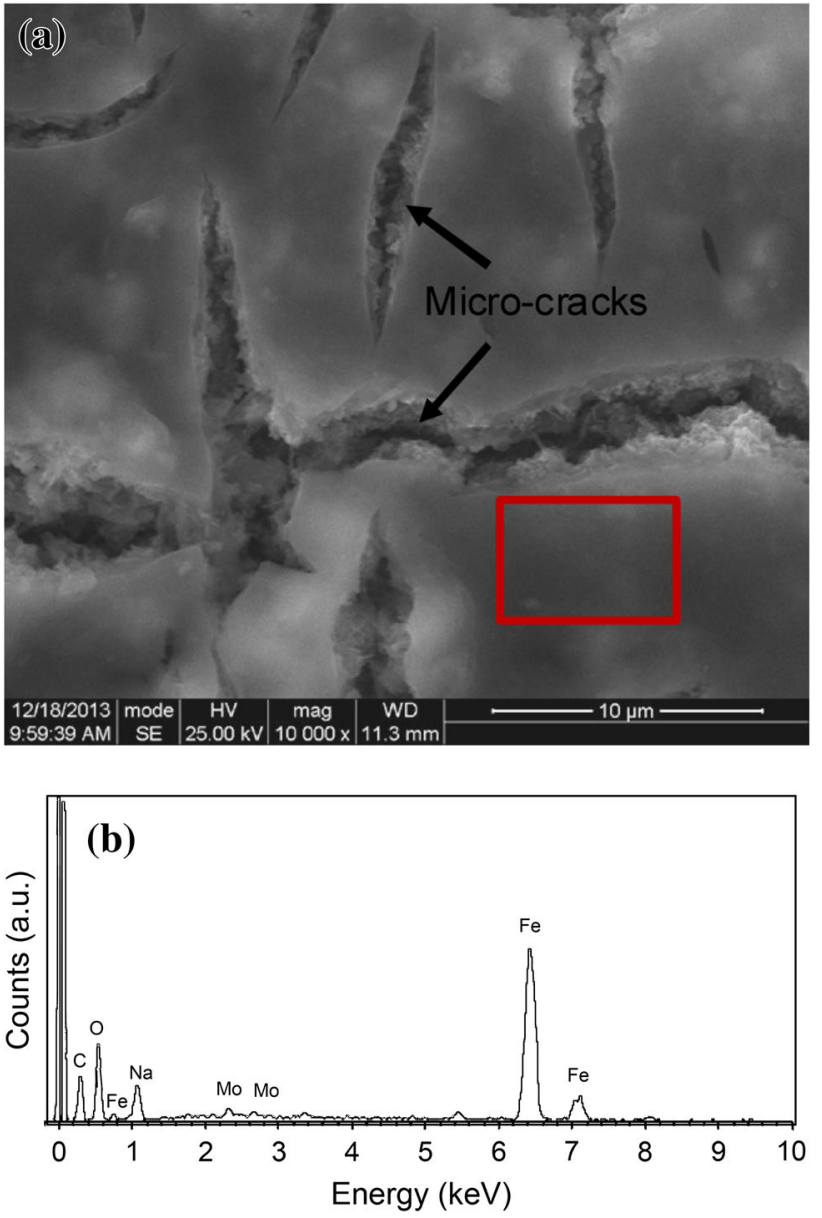

Fig. 7 Surface morphology of the tannic conversion layer a; EDX result of the selected area in $\mathbf{a} \mathbf{b}$

fracture; and (3) the mixture of interfacial fracture and cohesive fracture.

Figure 9 presents the failure morphology of the sample without the tannic converter treatment after the adhesion test measurement. Obviously, the failure mode is the

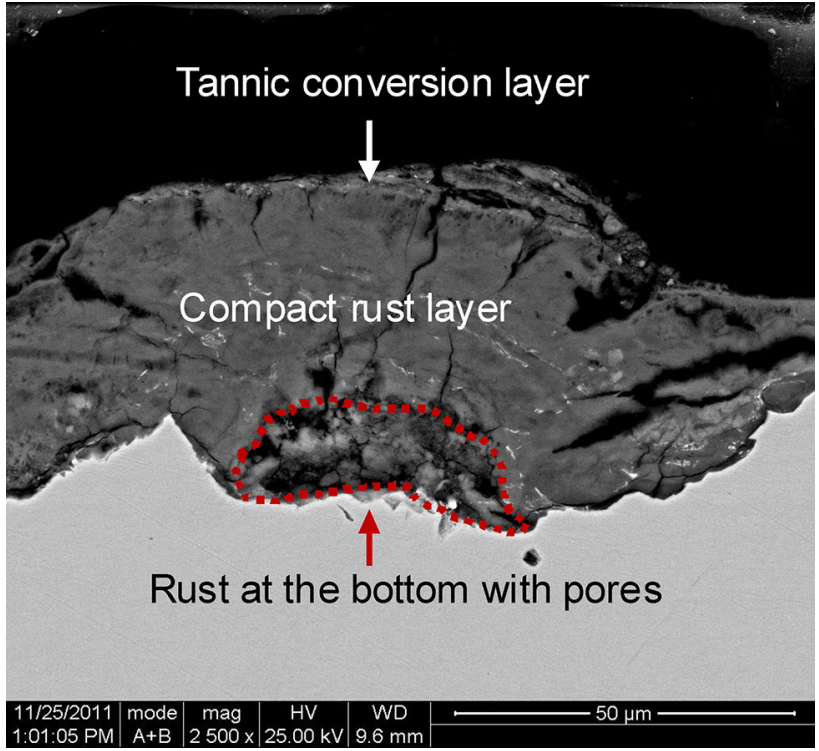

Fig. 8 Cross-section morphology of the tannic conversion layer

mixture of interfacial fracture and cohesive fracture. The interfacial fracture occurs between the epoxy coating and the rust layer, and the cohesive fracture appears within the rust layer accounted for most of fracture area. It reveals that the cohesive fracture in the rust layer is the main failure mode, and the rust layer is the weakest link to the coating system.

Figure 10 illustrates the failure morphology of the sample with the tannic converter treatment after the adhesion test measurement. The coating system also exhibits the mixture of the interfacial fracture and cohesive fracture. The interfacial failure occurs between the epoxy coating and the conversion layer. The FTIR spectrum in Fig. 11 shows that the components adhered to the adhesion strength tested dolly are lepidocrocite and ferric tannate. Besides, the SEM image of the failure substrate (Fig. 12) 

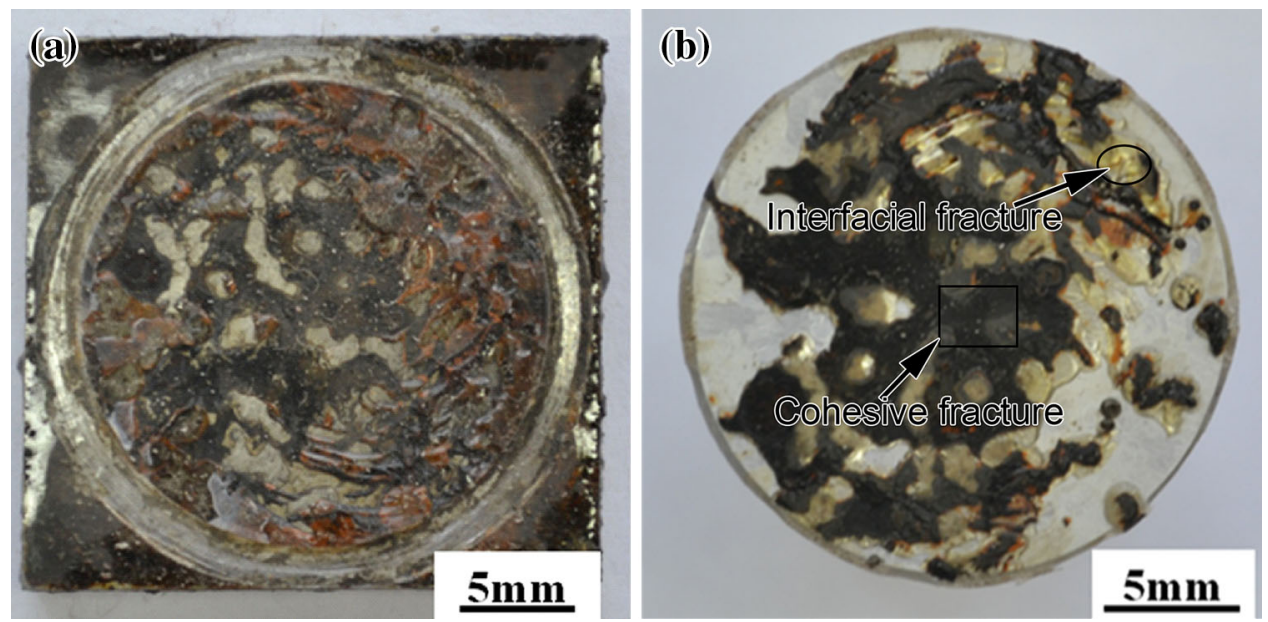

Fig. 9 Failure morphologies without the tannic converter treatment after the adhesion test measurement: a failure substrate; b relative test dolly
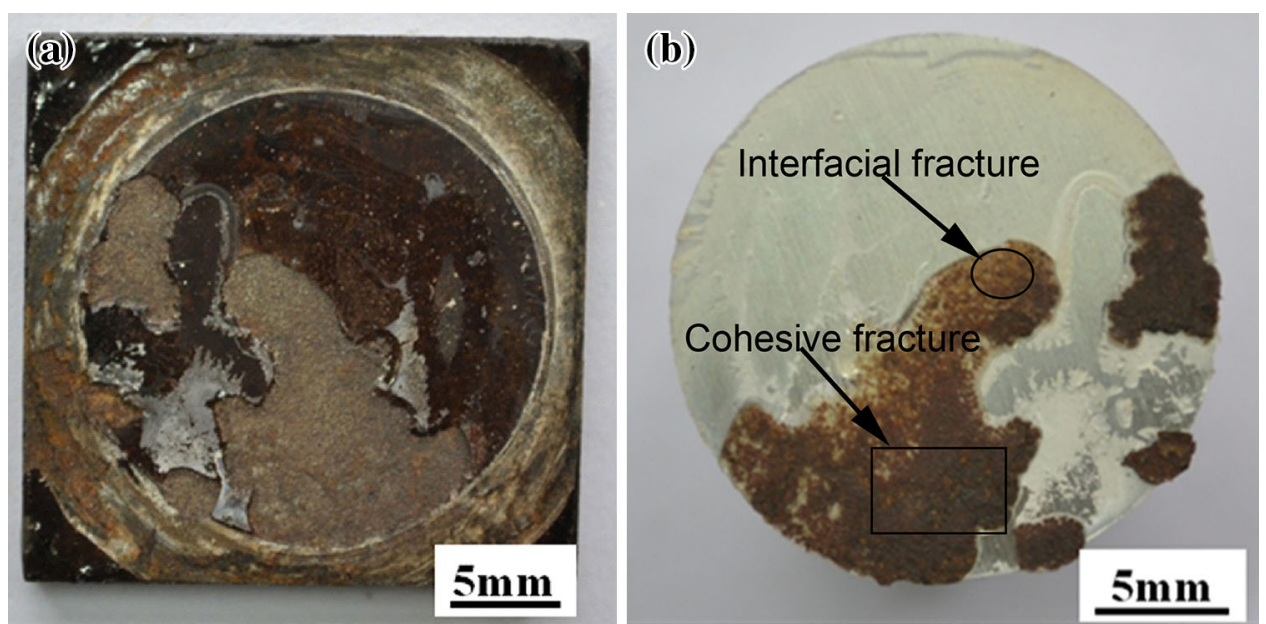

Fig. 10 Failure morphology with the tannic converter treatment after the adhesion test measurement: a failure substrate; $\mathbf{b}$ relative test dolly

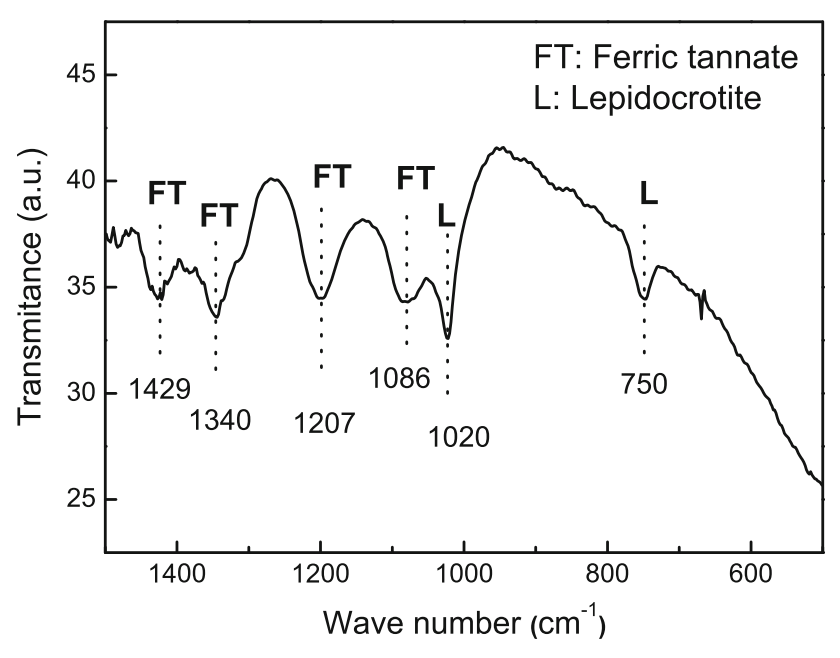

Fig. 11 FTIR spectrum of the components adhered to the test dolly with the tannic converter treatment indicates the presence of lepidocrocite with lamellar structure, but there is no trace of the ferric tannates with typical micro-cracked structure, which confirms that the residual components at the substrate are remainder rust. The former two aspects confirm that the cohesive fracture takes place in the remainder rust layer. In addition, the cohesive fracture accounted for most of fracture area shows that the cohesive fracture of the remainder rust layer is the main failure mode, and the remainder rust layer is the weakest link to the coating system.

\section{Discussion}

The results suggest that the main component of the rust generated by the salt spray test in the laboratory is lepidocrocite with lamellar and porous structure, which is 


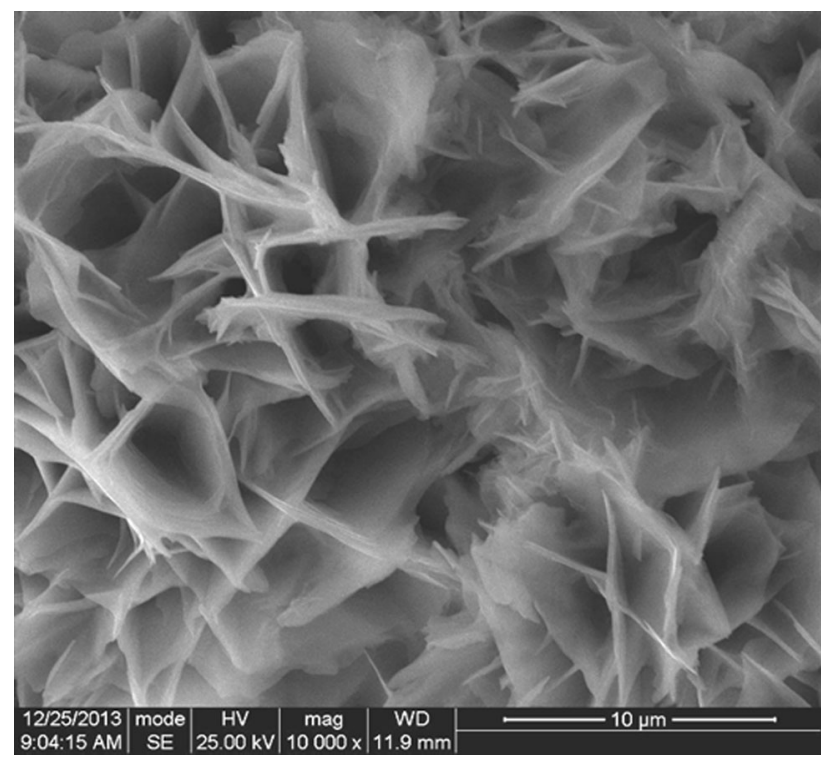

Fig. 12 Micro morphology of the failure substrate with the tannic converter treatment

similar to the samples after 36 months outdoor exposure in Shenyang. This confirms that the salt spray test can accurately modify the actual rust formation.

Before the tannic converter treatment, the porous rust layer is the weakest link and can cause the reduction in adhesion strength for the coating system. After the tannic converter treatment, micro-cracked tannic conversion layer forms on the surface. On the other hand, the tannic converter penetrates into the inner rust and reacts with part of it, leading to the increase of the compactness of the inner rust [9]. The improvement of compactness in the rust layer also enhances its cohesion. In addition, when epoxy coatings is applied, the epoxy resin can easily penetrate along the micro-cracks inside the rust layer, and the existence of a large number of micro-cracks can remarkably increase the contact area between the epoxy and the rust layer, which can enhance the interfacial adhesion strength by mechanical anchoring effect.

The reaction mechanism of the tannic and rust has been investigated by some researchers. It is believed that three tannate ions reacted with one ferric ion to form a stable cooctahedral ordination compound. In addition, the tannin molecules are mixtures of polyphenols with hydroxyl $(\mathrm{OH})$ groups in ortho positions, each molecule could react with a number of ferric ions [7]. The two aspects lead to form a network structure. Furthermore, some investigations [8, 31, 32] showed that the tannins reacted with rust in three steps. First, the rust dissolves in the acidic environment to release $\mathrm{Fe}^{3+}$ (Eq (1)). Second, due to the reduction of the capability of tannins, the $\mathrm{Fe}^{3+}$ can be reduced to $\mathrm{Fe}^{2+}$ ions that can complex with tannins to form ferrous-tannates
(Eqs. (2)-(4)). Finally, the ferrous-tannates are converted to ferric tannates with the presence of oxygen (Eqs. (5)(7)).The specific reaction mechanism of the tannins and rust is explained by the following path:

$\mathrm{FeOOH}+3 \mathrm{H}^{+} \rightarrow \mathrm{Fe}^{3+}+2 \mathrm{H}_{2} \mathrm{O}$.

Followed by the reduction of $\mathrm{Fe}^{3+}$ ions and reaction with the tannins,

$n \mathrm{Fe}^{3+}+n \mathrm{e}^{-} \rightarrow n \mathrm{Fe}^{2+}$,

tannins $\rightarrow$ tannates $+n \mathrm{e}^{-}+n \mathrm{H}^{+}$,

$n \mathrm{Fe}^{3+}+$ tannins $\rightarrow\left(\mathrm{Fe}^{2+}\right){ }_{n}$ tannate $+n \mathrm{H}^{+}$,

Consequently,

$\left(\mathrm{Fe}^{2+}\right)_{n}$ tannate $\rightarrow\left(\mathrm{Fe}^{3+}\right)_{n}$ tannate $+n \mathrm{e}^{-}$,

$\frac{n}{4} \mathrm{O}_{2}+n \mathrm{H}^{+}+n \mathrm{e}^{-} \rightarrow \frac{n}{2} \mathrm{H} 2 \mathrm{O}$,

$\left(\mathrm{Fe}^{2+}\right)_{n}$ tannate $+\frac{n}{4} \mathrm{O} 2+n \mathrm{H}^{+} \rightarrow\left(\mathrm{Fe}^{3+}\right)_{n}$ tannate $+\frac{n}{2} \mathrm{H}_{2} \mathrm{O}$.

The XPS results show that the $\mathrm{MoO}_{4}{ }^{2-}$ was reduced to $\mathrm{MoO}_{x}(2.5<x<3)$ which indicates that the following reaction might take place accelerating the formation of the tannic conversion layer.

$$
\begin{aligned}
& \left(\mathrm{Fe}^{2+}\right)_{n} \text { tannate }+\frac{n}{6-2 x} \mathrm{MoO}_{4}^{2-}+\frac{n(4-x)}{3-x} \mathrm{H}^{+} \\
& \quad \rightarrow\left(\mathrm{Fe}^{3+}\right)_{n} \text { tannate }+\frac{n}{6-2 x} \mathrm{MoO}_{x}+\frac{n(4-x)}{6-2 x} \mathrm{H}_{2} \mathrm{O} .
\end{aligned}
$$

According to the reaction mechanism, the hydrogen ions are involved in most of the reaction, which indicates that the $\mathrm{pH}$ is one of the factors affecting the formation of the tannic conversion layer [33]. Equation (1) reveals that the rust would show high dissolution rate in acidic $\mathrm{pH}$, but the high acidic $\mathrm{pH}$ would restrain the reaction of $\mathrm{Fe}^{3+}$ and tannins (Eq (4)). Therefore, a suitable $\mathrm{pH}$ is necessary for the effective formation of the tannic conversion layer. And the adding critic acid in the tannic acid solution is one strategy for an appropriate $\mathrm{pH}$ adjustment.

Although the adhesion is enhanced by the tannic acid treatment, it still does not satisfy the actual needs. The failure analysis shows that the remainder rust layer is still the weakest link in the coating system. According to Rahim et al. [31], the tannic acid reacts with the outer rust rapidly producing the dense conversion layer which increases the outer layer impermeability. The cross-section morphology after the tannic treatment (Fig. 8) shows that the outer layer is compact, which is in agreement with the result of Rahim et al. The outer compact layer prevents the penetration of the tannic acid into the inner rust, and some of pores remain at the bottom of the rust. The remaining pores limit 
the adhesion enhancement. For further enhancement of the adhesion strength, the tannic acid solution should penetrate to the bottom of the inner rust and react further to form a compact conversion layer. Therefore, improving the diffusion rate of the tannic acid solution and controlling the reaction rate of the tannic acid with the rust are the pivotal issues to further enhance the adhesion.

\section{Conclusion}

An eco-friendly rust converter composition based on tannic acid was optimized for the rusted structural steel by orthogonal experiment, and the adhesion of the epoxy topcoating system was evaluated. After the treatment of the tannic converter, the adhesion strength of the coating system was enhanced from 1.93 to $5.97 \mathrm{MPa}$. This adhesion improvement was attributed to two aspects: one is the formation of the micro-cracked tannic conversion layer, which could reinforce the anchoring of epoxy coating through the pinning effect; the other is the increase in the compactness of the rust layer after the tannic acid treatment. The failure analysis suggested that the remainder rust was still the weakest link in the coating system. To further optimize the formulation basic on tannic acid for better industrial applications, the effective penetration enhancer and suitable reaction rate control agents are needed.

Acknowledgments This work was financially supported by the National Natural Science Foundation of China (Nos. 51001108 and 51131007) and the National Basic Research Program of China (No. 2010CB934604). The authors are also grateful to Prof. G.N.K. Ranesh Bapu for the modification of English.

\section{References}

[1] L.K. Aggarwal, P.C. Thapliyal, S.R. Karade, Prog. Org. Coat. 59, 76 (2007)

[2] L.M. Ocampo, I.C.P. Margarit, O.R. Mattos, S.I. Córdoba-deTorresi, F.L. Fragata, Corros. Sci. 46, 1515 (2004)

[3] S.N. Roselli, B. del Amo, R.O. Carbonari, A.R. Di Sarli, R. Romagnoli, Corros. Sci. 74, 194 (2013)

[4] A. Collazo, X.R. Novoa, C. Perez, B. Puga, Electrochim. Acta 53, 7565 (2008)

[5] A.A. Rahim, M.J. Kassim, E. Rocca, J. Steinmetz, Corros. Eng., Sci. Technol. 46, 425 (2011)

[6] A.A. Rahim, E. Rocca, J. Steinmetz, M.J. Kassim, Corros. Sci. 50, $1546(2008)$
[7] J.A. Jaen, L. Gonzalez, A. Vargas, G. Olave, Hyperfine Interact. 148-149, 227 (2003)

[8] A.A. Rahim, E. Rocca, J. Steinmetz, M.J. Kassim, R. Adnan, M.S. Ibrahim, Corros. Sci. 49, 402 (2007)

[9] A. Collazo, X.R. Novoa, C. Perez, B. Puga, Electrochim. Acta $\mathbf{5 5}, 6156(2010)$

[10] J.A. Jaen, E.Y. Arauz, J. Iglesias, Y. Delgado, Hyperfine Interact. 148-149, 199 (2003)

[11] C.A. Barrero, L.M. Ocampo, C.E. Arroyave, Corros. Sci. 43, $1003(2001)$

[12] ISO 8501-1, Preparation of Steel Substrates Before Application of Paints and Related Products-Visual Assessment Cleanliness-part 1: Rust Grades and Preparation Grades of Uncoated Steel Substrates and of Steel Substrates After Overall Removal of Previous Coatings (ISO, Geneva, 2007)

[13] ASTM B 117-95, Standard practice for operating salt spray (Fog) apparatus, in Annual Book of ASTM Standards, Vol. 03.02, (ASTM, West Conshohocken, 1996)

[14] Y.T. Ma, Ph.D. Thesis, Institute of Metal Research (Chinese Academy of Sciences, Shenyang, 2009)

[15] ISO 2808, Paints and Varnishes-Determination of Film Thickness, Classification (ISO, Geneva, 1997)

[16] L. Tao, S.Z. Song, S.Y. Wang, X.Y. Zhang, M. Liu, F. Lu, Mater. Sci. Eng., A 476, 210 (2008)

[17] G.Z. Liang, J.R. Meng, L. Zhao, Polym. Plast. Technol. Eng. 43, 341 (2004)

[18] J.B. Bajat, I. Milosev, Z. Jovanovic, V.B. Miskovic-Stankovic, Appl. Surf. Sci. 256, 3508 (2010)

[19] S.R. Rau, B. Vengadaesvaran, K. Ramesh, A.K. Arof, J. Adhesion 88, 282 (2012)

[20] Z. Qian, S. Zhou, R. Liu, X. Hu, F. Zhao, L. Niu, China Patent CN102383122-A, (2012)

[21] Y.W. Wei, T. Liu, K. Qiu, Y. Xie, China Patent WO2012024680-A1, (2012)

[22] ISO 4624, Paints and Varnishes-Pull-off Test For Adhesion (ISO, Geneva, 2002)

[23] I. Díaz, B. Chico, D. de la Fuente, J. Simancas, J.M. Vega, M. Morcillo, Prog. Org. Coat. 69, 278 (2010)

[24] X.Y. Zhang, P. Chen, X.T. Kang, M.X. Chen, Q. Wang, J. Appl. Polym. Sci. 123, 2945 (2012)

[25] A. Raman, B. Kuban, A. Razvan, Corros. Sci. 32, 1295 (1991)

[26] J. Iglesias, E.G.D. Saldana, J.A. Jaen, Hyperfine Interact. 134, 109 (2001)

[27] C.H. Bichler, H.C. Langowski, M. Bischoff, U. Moosheimer, Paper present in 39th Annual Technical Conference of the Society of Vacuum Coaters, 5-10 May 1996, Philadelphia, (1996)

[28] M. Anwar, C.A. Hogarth, R. Bulpett, J. Mater. Sci. 24, 3087 (1989)

[29] D.C. Smith, B. Mcenaney, Corros. Sci. 19, 379 (1979)

[30] L.L. Zhai, G.P. Ling, Y.W. Wang, Int. J. Adhes. Adhes. 28, 23 (2008)

[31] A.A. Rahim, J. Kassim, Recent Pat. Mater. Sci. 1, 223 (2008)

[32] A.A. Rahim, E. Rocca, J. Steinmetz, M.J. Kassim, M.S. Ibrahim, H. Osman, Food Chem. 107, 200 (2008)

[33] O. Lahodny-Sarc, F. Kapor, Mater. Corros. 53, 264 (2002) 